\title{
CIÊNCIA E TECNOLOGIA NA AGRICULTURA MEXICANA
}

\author{
SCIENCE AND TECHNOLOGY IN AGRICULTURE IN MEXICO
}

Renato Rodrigues Lugui - Astra.renato@gmail..com

Nathalia Maria Soares - nathalia.soares@ fatectq.edu.br

Faculdade de Tecnologia de Taquaritinga (FATEC) - SP - Brasil

DOI: 10.31510/infa.v15i2.510

\begin{abstract}
RESUMO
Este artigo analisa e discute o surgimento de tipos de agricultura a científica, a industrial, a alternativa e a revolução verde. Os três primeiros tipos foram desenvolvidos nos países industrializados, enquanto a revolução verde teve lugar em países em desenvolvimento. A necessidade de desenvolver quadros legais sobre o uso dos recursos naturais na agricultura, para limitar os danos para os processos do ecossistema de eutrofização, poluição de aquíferos, erosão, salinização e emissão de gases de efeito estufa. Também é discutido que a pesquisa mexicana historicamente focado no mais produtivo agroecossistema, com pouca atenção para a marginal agroecossistemas e ignorando a etnoagricultura. $\mathrm{O}$ paradigma da agricultura alternativa é apresentado como, pertencente à linhagem da agricultura científica, economicamente viável para a pequena agricultura, e a menos agressivo contra o ecossistema natural. E por isso, sugeriu que a adoção desse paradigma ajudaria resgatar o setor de pequenas propriedades agrícolas e a segurança alimentar.
\end{abstract}

Palavras-chave: México, desenvolvimento, agricultura, economia, segurança.

\begin{abstract}
Summary This article analyzes and it discusses the appearance of agriculture types the scientific, the industrial, the alternative and the green revolution. The first three types were developed at the industrialized countries, while the green revolution had room in developing countries. The need to develop legal pictures on the use of the natural resources in the agriculture, to limit the damages for the processes of the eutrofização ecosystem, pollution of watery, erosion, salinização and emission of greenhouse effect gasses. It is also discussed that the Mexican research historically focused in the most productive agroecossistema, with little attention for the marginal agroecossistemas and ignoring the etnoagricultura. The paradigm of the alternative agriculture is presented as, belonging to the lineage of the scientific agriculture, economically viable for the small agriculture, and the least aggressive against the natural ecosystem. And for that, he/she suggested that the adoption of that paradigm would help to rescue the section of small agricultural properties and the alimentary safety.
\end{abstract}

Keywords: Mexico, development, agriculture, economy, safety. 


\section{INTRODUÇÃO}

Os recursos naturais na agricultura do México exigem atualização à luz do conhecimento científico e tecnológico, para limitar o efeito prejudicial de algumas práticas agrícolas no ecossistema. O campo mexicano tem recursos humanos e recursos naturais que permitem potencialmente produzir de forma sustentável os alimentos e fibras que requerem uma população pelo menos 50\% maior que a do México (Turrent e Cortés, 2005).

O quadro legal mexicano que regula diretamente o uso do campo tem como eixo central o Artigo Constitucional 27, que determina a estrutura e posse da terra, com três leis reguladoras: Direito Agrário, Direito Florestal e Direito Nacional da Água . As seguintes leis são complementadas pelas seguintes leis: Lei Federal de Sanidade Vegetal, Lei Federal de Sanidade Animal, Lei de Desenvolvimento Rural Sustentável, Lei de Certificação de Produção e Comercialização de Sementes, Lei Geral de Desenvolvimento Florestal Sustentável e Lei Geral de Equilíbrio Ecológico e Proteção do meio ambiente, este quadro de leis, regulamentos e normas oficiais mexicanas tem orientado o uso do campo para fins definidos pela história do próprio país. No entanto, as experiências agrícolas e ecológicas mundiais do último terço do século XX fornecem lições críticas sobre o agroecossistema global, como produtor de alimentos e fibras, e a relação entre esse agroecossistema e o ecossistema natural, que não são explicitamente abordados no quadro do México (leis, regulamentos e normas oficiais mexicanas) para o uso do campo. Entre esses ensinamentos estão: a revolução verde como um fator chave no aumento da produção de alimentos e, ao mesmo tempo, uma causa central da erosão da diversidade genética de culturas básicas em países do terceiro mundo, erosão de solos, eutrofização de corpos hídricos, contaminação de aquíferos subterrâneos, e a emissão de gases termoativos, como externalidades da atividade agrícola. Essas experiências devem ser assimiladas ao marco legal de todos os países para buscar a sustentabilidade dos recursos naturais, produzindo os alimentos e fibras demandados pelos humanidade.

O objetivo desta análise é fazer uma breve histórica do desenvolvimento global do conhecimento agrícola e mostrar os antecedentes como forma de alertar sobre as áreas do marco legal mexicano que requerem enriquecimento conceitual. 


\section{CIÊNCIA E TECNOLOGIA NA AGRICULTURA}

No período desde a invenção da agricultura, possivelmente 80 séculos aC, até o século XVIII, a humanidade acumulou uma grande quantidade de conhecimento empírico sobre o cultivo e uso de plantas e animais, o que permitiu o florescimento de suas grandes civilizações. A nixtamalização, a fermentação, irrigação, o arado, a roda, arneses para tração animal, adubos, adubos verdes e cal já conhecidos e usados no cultivo e o uso de um grande inventário de espécies cereais, leguminosas, oleaginosas, raízes e tubérculos e outras espécies que produzem alimentos e fibras úteis. Segundo a Asimov (1989), por volta do século XVIII, ciência, separada da teologia, tinha produzido o método científico (Descartes em 1637), descobriu o mundo dos microrganismos (Van Leeuwenhoek, 1676), Brand havia descoberto em 1669 o elemento fósforo, Rutherford em 1772 ao nitrogênio, Priestley ao oxigênio em 1774 e também a relação entre plantas e $\mathrm{CO}_{2}$ e Ingenhousz em 1779 ao fenômeno da fotossíntese; Linnaeus já havia publicado, em 1735, seu trabalho nos Sistemas da Natureza.

$\mathrm{O}$ século XIX trouxe a aplicação do pensamento científico à agricultura (Tisdale e Nelson, 1975, Asimov, 1989). Os cientistas que mais contribuíram para o seu desenvolvimento inicial foram os químicos, Jean Baptist Boussingault que estabeleceu as bases do método de experimentação de campo; Justus von Liebig que formulou sua Lei do Mínimo na resposta das culturas; Lawes que patenteou o primeiro processo de obtenção do fertilizante superfosfato simples; Lawes e Gilbert que iniciaram em 1843 os primeiros experimentos clássicos em Rothamsted, Inglaterra (que continuam sem interrupção 160 anos depois); Thomas Way que demonstrou, em 1852, a propriedade da troca de cátions do solo. Microbiologistas do último quartel do século demonstraram a ação bacteriana na oxidação do nitrogênio amoniacal do solo, enquanto Hellriegel e Wilfarth concluíram que deveria haver organismos bacterianos nos nódulos radiculares das leguminosas e que estes organismos tinham a capacidade de assimilar o nitrogênio atmosférico. e convertê-lo em formas utilizáveis pelo plantas.

Em 1865, o monge austríaco Gregorio Mendel publicou seu trabalho sobre a herança de alguns caracteres simples da ervilha. Mas tarde, em 1915, Morgan publicou seu trabalho sobre a herança de características ligadas no mesmo cromossomo. Em 1939, o Müller químico encontrada o DDT molécula orgânica, que era conhecida desde 1873, sendo tóxica para os insetos. Fisher contribuiu substantivamente durante o segundo terço do século XX para o desenvolvimento de estatísticas como suporte para o método de campo. Mitscherlich, em 1909, 
e Jenny, em 1941, formularam expressões da lei do rendimento das culturas . O segundo autor pronúncia na lei que o rendimento da cultura é uma função do solo, clima, manejo da planta e biota. Em 1953, Watson e Crick propuseram a estrutura do DNA. Kary Mullis descobre, na década de 1980, a reação em cadeia da polimerase. E em 1965, De Witt publica seu trabalho de modelar o desenvolvimento da cobertura vegetal de uma cultura, enquanto no último terço do século ocorre um desenvolvimento espetacular na capacidade tecnológica da computação, bem como a notável redução do custo para sua produção.

$\mathrm{Na}$ medida em que o conhecimento científico foi aplicado às regiões agrícolas do mundo, tornou-se claro que uma parte substancial do que o conhecimento era, dependia das condições locais. Assim a dose ótima de fertilizante para uma cultura e seu rendimento dependeu das manifestações de fatores incontroláveis para o produtor, como solo, clima e biota, além de seu manejo agronômico (variedade, data de semeadura, densidade populacional, proteção, etc.). Tornou-se claro que os fatores de rendimentos foram inativos. Essa interação pode ser positiva ou negativa. Em suma, a experiência mostrou, inequivocamente, que parte do conhecimento agrícola alcançado não era universalmente extrapolado. Em adição, agricultura científica exigia conhecimento do solo dos recursos naturais, clima e biota per se para ser sustentável. Como um resultado e, como uma regra, a aplicação prática do conhecimento para uma região agrícola exigem esforços em pesquisa, educação e disseminação do conhecimento, que só a intervenção do Estado nos planos e longos - investimentos de curto prazo, poderia ser abordada sucesso.

\section{REVOLUÇÃO VERDE}

No final do segundo terço do século XX, o mundo já estava dividido entre os países que conseguiram realizar seu trabalho no setor agrícola e aqueles que não o fizeram. Entre estes últimos estavam os da Ásia e África, onde a ameaça de fome era iminente devido ao desequilíbrio observável entre suas taxas de desenvolvimento demográfico, aumento na produção de alimentos e sua escassez de moeda estrangeira. Embora nesses países, e em muitos outros, houvesse regiões extensas com solos e climas benignos para produção de alimentos ou que tivessem infraestrutura de irrigação, pouco foi investido em pesquisa agrícola, educação e disseminação de conhecimento. O rendimento agrícola foi baixo mesmo em suas regiões potencialmente mais produtivas. Não foi a solução para extrapolar o conhecimento científico e 
suas ferramentas de países desenvolvidos, porque eles não funcionariam sem a adaptação (Redação Pensamento Verde, 2013).

Um pequeno grupo de agrônomos encontrou uma maneira genética de quebrar parcialmente a barreira da não-extrapolabilidade na aplicação do conhecimento agronômico em dois dos três cereais mais consumidos no mundo: arroz e trigo. No caso do trigo, o conhecimento foi desenvolvido no México por Borlaug e seus colaboradores, nas décadas de 1950 e 1960. A barreira poderia ser superada pelo conhecimento da genética clássica, reunindo em uma única planta os alelos apropriados: da herança do caráter "palha curta" (eliminar o problema do acamamento da lavoura na presença de fertilizantes e irrigação), da resistência genética às doenças prevalentes e conferir ampla adaptabilidade às condições agroclimáticas diferente embora o caráter de "palha curta" fosse uma solução permanente, o da resistência genética a doenças exigia uma abordagem do conhecimento epidemiológico e busca e incorporação contínuas de alelos de resistência a uma ameaça que muda geneticamente. $\mathrm{O}$ objetivo foi alcançado no México, através de uma estratégia abrangente de cruzamentos, inoculações e alternância entre um ambiente de seleção quase ao nível do mar (ciclo outonoinverno) e outro a uma altitude de 2600 metros nos Altos Vales do México (ciclo Primavera Verão).Este tratamento permitiu que Borlaug e seus colaboradores quebrassem a barreira da não-extrapolabilidade genética, em uma zona mundial com um desenvolvimento latitudinal semelhante ao de México (Bezerra, 2018).

Nesta faixa está localizada uma seção densamente povoada da Ásia e da África, na época ameaçada pela fome. As novas variedades de trigo expressaram indistintamente sua potencialidade produtiva por toda essa zona mundial. Outros fatores de manejo agrícola de culturas como fertilização, densidade populacional, proteção contra pragas, plantio direto, etc. tratamento cientificamente teve menos elegante, em resposta à escassez aguda de profissionais e infraestrutura na área alvo da estratégia de recursos humanos. Esses fatores foram abordados com uma abordagem de grande visão que ignorou muito do que foi aprendido na agronomia clássica: rotação de culturas, proteção do solo epipedônico e procedimentos para a dosagem de fertilizantes e pesticidas. Esta é a origem do segundo componente da estratégia que foi reconhecido como um "pacote tecnológico". Está limitação é que os autores da estratégia, mais tarde apelidado de "revolução verde", estreitou seu domínio para as planícies de maior qualidade agrícola, ou que estavam disponíveis infraestrutura de irrigação (Significado Revolução Verde, 2018). 
O reconhecido sucesso da Revolução Verde, em termos de aumento de produtividade, levou à adoção da estratégia a todo custo, uma vez que ela foi aplicada a outras culturas e as terras ecologicamente frágeis. Culturas alimentares múltiplas e compostas, centenas de espécies e ecótipos de espécies, todas típicas da agricultura tradicional, foram substituídas por culturas simples de poucas espécies e variedades melhoradas sob o regime de monocultura. Essa simplificação abriu fronteiras para a ampla adoção de agroquímicos sob padrões mínimos de regulamentação. A erosão genética teve uma magnitude substantiva, a erosão hídrica também foi incentivada em centenas de bacias hidrológicas. A revolução verde fez aprofundar as diferenças entre as rendas dos produtores e dos produtores de negócios de corte, sendo assim, considerada pequena. A maior escala de produção e o acesso rápido aos serviços do primeiro, aumentaram sua competitividade e poder de gestão em relação aos segundos (Santikarn-Kaosaard e Rerkasem, 2000).

Infelizmente, o sucesso líquido da revolução verde na produção de alimentos foi mal interpretado, fora da academia, como uma demonstração de que os investimentos em pesquisa agrícola local, no conhecimento dos recursos naturais per se e na formação de recursos humanos, não seria estritamente prioritário para alcançar a segurança alimentar. É comum que esta posição seja atualmente compartilhada por muitos governos dos países do mundo em desenvolvimento, dentre eles o México. Na busca para corrigir os problemas causados pela revolução verde, as estratégias conhecidas como LEISA (baixa-entrada-sustentávelagricultura), agricultura orgânica e uma correção do paradigma da revolução verde progrediram no mundo em desenvolvimento (Fernández e Moreno-Dahme, 1998).

\section{AGRICULTURA DO MÉXICO}

Uma classificação arbitrária da agricultura no México que é útil para nossos propósitos consiste em quatro categorias: a revolução verde do tipo agricultura (sob irrigação ou clima ameno, norte do país, Bajío, vales altos, costas tropicais e subtropicais do Golfo do México e do Pacífico); a agricultura marginal (pela qualidade de suas terras e clima, pela pequenez de suas propriedades e acesso a serviços, localizada no planalto semiárido do norte, os altos vales, o semi-árido Bajío e os Mixtecas) ; a etnoagricultura (sedentária ou roza-tum baquema, desenvolvida nas serras, nas costas do Golfo do México e no Caribe e no Pacífico); e a agricultura orgânica (nichos de alta qualidade agrícola localizados em cadeias montanhosas, costas, vales alta) (Freitas, 2018). 
A pesquisa agrícola que tem sido historicamente realizada no México tem se concentrado quase exclusivamente na produtividade dos recursos naturais (solo, água, clima e germoplasma) das regiões mais produtivas, classificada aqui como o tipo de revolução verde. No entanto, nessas regiões, a pesquisa para o conhecimento desses recursos, em si, foi quase ignorada, o estudo dos efeitos negativos das práticas agrícolas, isto é, das externalidades ecológicas, também foi negligenciado. As exceções são o que se aprendeu sobre drenagem e salinização nos distritos de irrigação e sobre a erosão hídrica nas encostas de alguns distritos de desenvolvimento rural.

Não há campo experimental no país que, localizado nas montanhas, atenda formalmente à etnoagricultura. O mesmo aconteceu em termos de desenvolvimento dos recursos humanos e institucionais. Também não existem planos estatais que procurem corrigir esta situação a médio ou longo prazo. Esta é a síndrome agrícola dos países subdesenvolvidos sitiada pelo seu crescimento demográfico. É óbvio que as omissões de pesquisas sobre a produtividade de recursos naturais.

Seria pertinente, enquanto avançando na direção de corrigir omissões na agricultura mexicana, aproveitar o conhecimento adquirido nos países industrializados sobre as externalidades ecológicas, a fim de atualizar a estrutura legal do interior mexicano. Esta estrutura vai servir principalmente como um guia para a ação futura no setor público na promoção da produção agrícola sustentável e proteção nacional dos ecossistemas contra a deterioração excessiva. A eutrofização, a contaminação de aquíferos profundos com nitritos e com moléculas agroquímicas devido ao seu uso desregulado, a salinização de terras irrigadas e o uso não profilático de agroquímicos são a ameaça iminente das regiões com atividades agrícolas. Isso pode ser inferido a partir do uso e abuso de agroquímicos por períodos de mais de 30 anos. A erosão do solo em declive nas categorias de agricultura marginal e etnoagricultura e danos diretos aos trabalhadores e famílias rurais pelo uso não-profilático de herbicidas, inseticidas em grãos armazenados em carcaças terminou e a queima de resíduos e recursos agrícolas como recurso tecnológico, são sua ameaça iminente (Luiselli, 2017).

Ele parece sensato para abraçar, como um país, o paradigma da agricultura alternativa com seu caso especial de agricultura biológica, quando aplicável, para o resgate dos tipos de exploração. Esta ação requer intensificar os esforços de investigação em áreas, agronomia clássica que estão sendo abandonados pelo estado, a reprodução de culturas clássica, entomologia e apto a patologia para o integrado de pragas e doenças, produtividade agronomia dos sistemas agrícolas, e o escopo do estudo dos recursos naturais utilizados na agricultura. 


\section{ATUALIZAÇÃO DO QUADRO JURÍDICO MEXICANO}

A Lei Geral do Equilíbrio Ecológico e Proteção Ambiental (LGEEPA), promulgada em 1998, em seu segundo artigo transitório que revoga a Lei de Conservação de Solo e Água, em vez promulgada em 1946. O LGEEPA aborda vários artigos relevantes para a proteção do solo, água, e biota (incluindo frações desses recursos dedicados à atividade agrícola). Esta lei foi reformada em 2003 para delimitar áreas de competência de outras leis e definir, por sua vez, os poderes de várias secretarias estaduais, como a Secretaria de Agricultura, Pecuária, Desenvolvimento Rural, Pesca e Alimentação (SAGARPA). Os regulamentos publicados da LGEEPA cobrem as áreas de impacto ambiental e ordem ecológica. O Escritório Federal de Proteção Ambiental (PROFEPA) foi criado como um instrumento para garantir a aplicação da LGEEPA. Também foram publicadas 29 normas oficiais mexicanas, das quais apenas duas, NOM-021-SEMARNAT-2000 e NOM-023 -SEMARNAT-2001, são pertinentes ao recurso do solo e os outros tratam de mais silvicultura do que questões agrícolas. A Lei Nacional das Águas aborda com grande detalhe, através da sua regulamentação de 1994, aspectos sobre o uso da água para fins de irrigação e outros usos não agrícolas. Não são outros regulamentos disponíveis ou oficiais padrões mexicanos para a operação de agricultura atual. Ele até agora indica que os problemas ecológicos mais notáveis do campo mexicano como a erosão do solo para uso agrícola, a eutrofização dos corpos d'água, a poluição de aquíferos e germoplasma com mais de 100 culturas de interesse econômico para o país e para o mundo, carecem de proteção efetiva.

Nenhum conhecimento do tipo pontual para o que desenvolveu no México, bem como o conhecimento dos países industrializados, que iria atualizar o quadro mexicano legal (regulamentos, regras oficiais, instituições) por meio de uma primeira aproximação que poderia ser aperfeiçoado depois de feito o esforço de investigação nacional. As regras oficiais mexicanas poderiam começar pelo estabelecimento de limites máximos de usos permitidos de fertilizantes e pesticidas, dependendo dos riscos ecológicos envolvidos. O risco imediato de germoplasma nativo de culturas domesticadas na Mesoamérica vem da importação e possível desregulação do germoplasma transgênico. Pode-se enfatizar o caso do risco assumido pelo milho e seus parentes selvagens: Teocintle e Tripsacum, dos quais nosso país é alvo de grandes discussões e opiniões (Turrent-Fernández, 2005). 


\section{CONCLUSÕES}

A pesquisa agrícola praticada no México historicamente tem sido focada na produtividade dos recursos naturais explorados na agricultura como solo, água, germoplasma das regiões mais produtivas e tem negligenciado a pesquisa para o conhecimento dos recursos naturais em si.

E com isso é necessário que se aprenda e se possa aplicar a experiência dos países industrializados nas externalidades ambientais da agricultura industrial e da agricultura familiar no último terço do século $\mathrm{XX}$ e a revolução verde nos países em desenvolvimento, para formulação de um quadro jurídico com uso sustentável dos recursos naturais na atividade agrícola do México.

Por tanto, se o México adota o desenvolvimento e aplica o paradigma da agricultura alternativa como uma solução que concilia segurança alimentar, agricultura em pequena escala e a proteção do agroecossistema, os problemas mais urgentes a deterioração dos recursos hídricos, do solo e biota para uso agrícola: erosão hídrica, a eutrofização das águas superficiais, contaminação de aquíferos profundos e perda de germoplasma de espécies nativas de uso agrícola seria ignorado até o momento pelos enquadramento legal mexicano.

\section{REFERÊNCIAS}

Asimov, I. 1989. Asimov's chronology of science and discovery. Harper Collins Publishers. New York.

Bezerra Juliana (2018). Revolução Verde. Disponível em: <https://www.todamateria.com.br/revolucao-verde/>. Acesso em: 10 de setembro de 2018.

Freitas Eduardo de (2018). Agropecuária no México. Disponível em: <https://mundoeducacao.bol.uol.com.br/geografia/agropecuaria-mexico.htm>. Acesso em: 21 de setembro de 2018.

Greene, C. y A. Kremen. 2003. U.S. organic farming in 2000-2001. Disponível em:<http:/www.ers.usda.gov/publications/aib780fm.pdf>. Acessado em: 18 de setembro de 2018.

Kimbrell, A. 2002. The fatal harvest reader: The tragedy ofindustrial agriculture. Island Press. Washington, DC. 
Luissile Cassio (2017). Agricultura no México. Disponível em: <http://www.iica.int/pt/content/agricultura-no-m\%C3\%A9xico>. Acessado em: 25 de setembro de 2018.

NAS (National Academy of Sciences). 1989. Alternative agriculture. The National Academy Press. Washington, DC.

Pesek, J. 2001. From a trail to a path to sustainable agriculture. Lecture presented before The John Pesek Colloquium on Sustainable Agriculture on March 1st 2001. Iowa State University. Ames, IA. Disponível em: $<\mathrm{http}: / / \mathrm{www}$.wallacechair.iastate.edu /endeavors/pesekcolloquium/pesek_lecture.doc>. Acessado em: 20 de agosto de 2018.

Redação Pensamento verde (2013). A revolução verde no Brasil e no Mundo. Disponível em: <https://www.pensamentoverde.com.br/atitude/a-revolucao-verde-no-brasil-e-no-mundo/>. Acesso em: 20 de agosto de 2018.

Santikarn-Kaosa-ard, M. y B. Rerkasem. 2000. The growth and sustainability of agriculture in Asia. Oxford University Press. New York.

Significado de evolução verde (2018). O que foi a Revolução Verde. Disponível em: <https://www.significados.com.br/revolucao-verde/>. Acesso em: 15 de setembro de 2018. Tisdale, S.L. yW.L. Nelson. 1975. Soil fertility and fertilizers. 3rd edition. MacMillan. New York.

Turrent-Fernández, A. y J.I. Cortés-Flores. 2005. Ciencia y Tecnología en la Agricultura Mexicana: II. Producción de alimentos. Terra Latinoamericana 23: 273-281.

Turrent-Fernández, A. y R. Moreno-Dahme. 1998. Producción sostenible de alimentos de origen vegetal en el mundo. Terra 16: 93-111. 